\title{
PRECARIZAÇÃO DO TRABALHO: ANÁLISE SOBRE AS CONDIÇÕES LABORAIS DOS MILITARES NO AMBITO ESTADUAL
}

\author{
Rogério Velasco Oliveira Gama \\ Policia Militar do Pará \\ rogerghandi@gmail.com \\ Luciana Rodrigues Ferreira \\ Universidade da Amazônia (UNAMA) \\ lucianarofer@gmail.com \\ Mauro Margalho Coutinho \\ Universidade da Amazônia (UNAMA) \\ mauro.margalho@unama.br \\ Plinio Victor Cardoso MoreiraAutor \\ Universidade da Amazônia (UNAMA) \\ pliniovcm@gmail.com
}

\begin{abstract}
Resumo
O estudo objetiva investigar as condições de trabalho dos militares do Estado do Pará, relacionando com conceitos de Precarização do trabalho. Parte-se do contexto sobre do conceito de precarização em novas formas de flexibilização funcional ou organizativa, para se debater as condições de trabalho dos militares, sob a percepção dos mesmos. Por meio de pesquisa Qualitativa, tipo exploratória, com técnicas de Estudo Documental e Questionário aplicado em um quartel do Corpo de Bombeiros Militar do Estado do Pará, no $1^{\circ}$ Grupamento Marítimo Fluvial, no período de 2017 e 2018. Com o resultado da análise dos dados coletados, tornou possível traçar o perfil socioeconômico da amostra, assim como, identificar que as instituições militares do Estado do Pará precisam avançar em muitos aspectos, principalmente na valorização do servidor militar e acima de tudo que o Governo possa alocar os recursos para a efetividades das atividades militares, na qual se apresenta alto índice de precarização.
\end{abstract}

Palavras-chave: Precarização do Trabalho. Segurança Pública. Políticas públicas.

\section{PREACARIZATION OF WORK: ANALYSIS ON MILITARY WORKING CONDITIONS IN THE STATE ENVIRONMENT}

\begin{abstract}
The study aims to investigate the working conditions of the military of the State of Pará, relating to concepts of precarious work. It starts from the context of the concept of precariousness in new forms of functional or organizational flexibility, to discuss the working conditions of the military, under their perception. Through qualitative research, exploratory type, with techniques of Documentary Study and Questionnaire applied in a barracks of the Military Fire Department of the State of Pará, in the 1st Fluvial Maritime Group, between 2017 and 2018. With the result of data analysis collected, made it possible to trace the socioeconomic profile of the sample, as well as to identify that the military institutions of the State of Pará need to advance in many aspects, especially in the valorization of the military servant and above all that the Government can allocate resources for the effectiveness of military activities, which presents a high rate of precariousness.
\end{abstract}

Keywords: Precariousness. Work. Public security. Public policy.

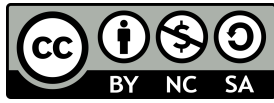




\section{INTRODUÇÃO}

O objetivo geral deste estudo é analisar as condições de trabalho na atividade policial militar, mais especificamente do bombeiro militar, com o intuito precípuo de refletir sobre a precarização do trabalho. As instituições, Polícia Militar e Bombeiro Militar, são componentes da Segurança Pública, como bem prevê o artigo 144 da Constituição Federal da República Federativa do Brasil de 1988, e nos parágrafos quinto e sexto da mesma, afirmam respectivamente que às polícias militares cabem a polícia ostensiva e a preservação da ordem pública; aos corpos de bombeiros militares, além das atribuições definidas em lei, incumbe a execução de atividades de defesa civil.

O parágrafo sexto do artigo 144, da referida Carta Magna, ressalta que as polícias militares e corpos de bombeiros militares, forças auxiliares e reserva do Exército, subordinamse, juntamente com as polícias civis, aos Governadores dos Estados, do Distrito Federal e dos Territórios.

Ao identificar as principais leis que tratam sobre os referidos profissionais, destaca-se: o Decreto-lei $\mathrm{n}^{\circ}$ 667, de 2 de Julho de 1969, que reorganiza as Polícias Militares e os Corpos de Bombeiros Militares dos Estados, dos Território e do Distrito Federal; a Lei nº 4491 de 28 de novembro de 1973 que dispõe sobre a remuneração dos Policiais Militares da PMPA e BMPA, e, a Lei Estadual n 5.251 de 31 de julho de 1985, que trata-se do Estatuto dos Policiais Militares e Bombeiros Militares, a título de curiosidade, tais dispositivos foram elaborados antes da redemocratização brasileira, ou seja, no período em que o Regime Militar estava vigente.

Ao analisar a regulação mencionada, percebe-se que não há uma delimitação de jornada de trabalho para essa categoria, o que interfere na vida social, na medida em que se extirpa do trabalhador a capacidade de planejamento de sua rotina em diferentes vertentes e atividades componentes das relações sociais, como por exemplo: familiar, estudantil, profissional.

Neste sentido, as discussões sobre condições de trabalho e o processo de exploração de trabalhadores, que sempre ganham maior ênfase na relação patrão/empregado do segundo setor, que é a iniciativa privada, a qual busca avidamente o lucro. Porém o caso dos servidores públicos, o do primeiro setor, no caso os militares estaduais, não só do Pará, mas de todas as unidades da federação, sentem na pele a exploração, a do Estado, ou seja, uma "espoliação" legalizada, mas por não ser uma atividade produtiva, ganha menos atenção.

Neste contexto o presente estudo apresenta como questão: em que medida as condições de trabalho, regulatórias e do cotidiano, interferem na valorização do trabalho do militar? 
O presente instrumento de estudo tem como objetivo geral, investigar a precarização no trabalho de policiais militares e bombeiros militares a partir da percepção dos militares ativos no agrupamento fluvial. Os objetivos específicos são: a) Identificar as características basilares sobre a categoria dos militares e regulação sobre o trabalho; c) Identificar as condições de trabalho e o discurso do militar sobre seu cotidiano.

Apresenta-se o estudo em cinco seções. A primeira é esta introdução. A Seção 2, realiza as abordagens teóricas sobre "trabalho", que serão norteadoras das análises e discussões do tema deste estudo, sendo dividida em três subseções. A Seção 3 é a Metodologia, ora empregada, para a consecução do trabalho, que é da análise da literatura científica (bibliográfica e documental) e a pesquisa de campo. Na Seção 4, percebe-se o resultado da pesquisa de campo, o que torna possível formular considerações sobre os dados apresentados. Por fim, as Considerações Finais sobre o resultado da pesquisa e do objeto de investigação.

\section{REFERENCIAL TEÓRICO}

\subsection{CONCEITOS E DEFINIÇÕES DE TRABALHO}

Trabalho pode ser entendido como o desprendimento de energia, do ponto de vista biológico, para confeccionar, produzir algo, bem como realizar uma dada tarefa. O resultado deste esforço gera um produto (com valor de uso e valor de troca), se formos analisar sobre a ótica do que Marx convencionou chamar, trabalho produtivo, que satisfará a demanda (consumidores) e em contrapartida, quem produz o bem ou serviço, receberá uma recompensa, valores monetários ou não, como forma de pagamento, o que permitirá que o agente possa manutenir sua força de trabalho diariamente, comprando gêneros alimentícios e vestuário, bem como o detentor dos meios de produção (empresário) aferirá seu lucro.

É importante destacar o que Ferreira (2012, p. 9), alinhavou sobre o elemento trabalho, numa perspectiva marxiana:

[...] O trabalho é uma atividade vital pela qual o homem se humaniza, desenvolve a sua sociabilidade e adquire autonomia intervindo na natureza por meio de sua ação propositiva, produzindo objetos que possuem utilidade social, adquirindo e refinando as suas habilidades [...].

O trabalho, portanto, em sua concepção genérica, tem este caráter de ser um elemento estruturante, no que diz respeito a organização e o equilíbrio da sociedade, tem uma função social. Para Marx (1983), o trabalho vem a ser um processo em que se relaciona o homem e o meio ambiente (natureza), em que o primeiro age, regula e controla seu metabolismo com a 
natureza. Produz mercadorias, que por conseguinte geram riquezas, satisfazem necessidades, sejam elas do estômago ou da fantasia, ou seja, satisfazem necessidades biológicas, bem como as de caráter de luxo e ostentação.

Ao projetarmos a observação sob a coletânea legislativa da República Federativa do Brasil, se pode, evidentemente, também analisar à luz da Ciência do Direito, o que vem a ser trabalho, mais especificamente pela Consolidação das Leis do Trabalho - CLT, de 1943, onde foi decretada pelo então Presidente, Getúlio Vargas. Na perspectiva da CLT, há espécies que se originam do termo "trabalhador", os quais seriam classificados em: empregados (carteira de trabalho assinada), trabalhador temporário, terceirizado, trabalhador autônomo, trabalhador eventual, trabalhador avulso, estagiário, cooperado, servidor público, trabalhador voluntário, mãe social e trabalhador religioso.

É importante destacar que existe uma diferenciação entre "emprego" e "trabalho", pois a ideia de emprego, nasceu de uma necessidade do Estado regular as relações trabalhistas, por meio de fomento de políticas sociais, em que se garantisse condições mínimas para o empregado fornecer sua mão-de-obra e manter sua integridade biológica, renovando diariamente sua energia. Já "trabalho" é um conceito mais generalista e polissêmico.

\subsection{ASPECTOS CONTEMPORÂNEOS DE TRABALHO E RELAÇÕES TRABALHISTAS}

Há de se destacar que as relações de trabalho sofreram grandes mutações, se formos investigar a história, dos tempos antigos, ou seja, pré-capitalista, onde os seres humanos buscaram se organizar em grupos, e dividirem as tarefas, ainda que de forma insipiente, porém dada as tecnologias rudimentares da época, foi o suficiente para satisfazer as necessidades do grupo e desenvolver instrumentos de trabalho, que propiciaram o aumento da produtividade, até a complexidade das relações trabalhistas do século XXI. Nesta fase pré-capitalista, inexistia a diferenciação de classes sociais, porém como destaca Hunt \& Sherman (2005, p. 9):

[...] Contudo, a distribuição sempre mais aperfeiçoada das tarefas, combinadas com instrumentos de trabalho mais sofisticados, propiciaram maior produtividade que possibilitou, ao menos para uma pequena parte da sociedade, livrar-se do fardo do trabalho cotidiano [...].

Portanto, o fator determinante para a criação de uma classe, que se livrava do fardo do trabalho cotidiano, ou seja, uma classe ociosa e que seria o embrião dos futuros grupos reduzidos, que seriam os detentores dos meios de produção, foi o crescimento da produtividade.

Com o advento da Revolução Industrial (a partir de 1760), a sociedade viu as classes mais abastardas se solidificarem cada vez mais em seus intentos empreendedores, e à custa da 
exploração dos trabalhadores, que em fases pretéritas (produção artesanal), tinham poder sobre sua força de trabalho, ou seja, dominavam todos os processos e cada fase da produção. Contudo, as "máquinas", bem dizer, os empresários (capitalistas) as introduziram e findaram por alienar o trabalhador, que passa a se sujeitar ao ritmo dos aparatos mecânicos, sendo apenas um mero executor de uma fase do processo de produção. O presente parágrafo vem a coadunar com o que preceitua Ferreira (2012, p. 7):

[...] No modo de produção capitalista o trabalho concreto, produtor de valores de uso, é subordinado ao trabalho abstrato, produtor de valores de troca. A posse privada dos meios de produção impossibilita que o trabalho se materialize como uma atividade emancipadora. O trabalho se transforma em uma atividade alienada e degradante[...].

O cientista social Karl Marx, um dos idealizadores, do que se chamou de socialismo científico, juntamente com Friedrich Engels, desenvolveu a teoria socialista, analisando de forma sistemática, crítica e científica o capitalismo. Elaborou a Teoria da mais-valia, que demonstra o modus operandi da exploração dos trabalhadores, via jornada de trabalho. O que é a mais-valia e como se processa?

Antes de apresentar o conceito de Mais-valia, é preciso necessariamente compreender o que é jornada de trabalho, pois a primeira está intimamente relacionada com a segunda. Então, jornada de trabalho é o período (geralmente em horas) em que o trabalhador se dispôs a executar funções capitaneadas pelos donos dos meios de produção. No estudo de Marx, jornada de trabalho seria a soma do "trabalho necessário", que é o tempo em que o operário produz o valor diário da sua força de trabalho, ou seja, o valor das substâncias necessárias para o seu sustento, com o "trabalho extraordinário", que é o tempo em que o operário produz valor para o capitalista, esse trabalho excedente, que gera um valor de retorno superior ao que recebeu como contrapartida de seu trabalho desempenhado, o que convencionou-se chamar de mais valia.

Portanto, o empregador contrata por uma determinada quantidade de dinheiro um trabalhador e define a carga horária também, mediante acordo entre as partes. Sendo o trabalho produtivo, o trabalhador produziu uma mercadoria, que o seu valor de troca seria o equivalente ao salário pago pelo empregador, porém o operário produziu em um tempo reduzido tal mercadoria e não poderá cruzar os braços, pois foi contratado para trabalhar "x" horas, e continuará a produzir mercadorias que darão retornos em grande escala ao capitalista, sem necessariamente receber algum bônus o operário. Tal entrave caracteriza a mais-valia.

Não havia leis para regular a proteção dos trabalhadores e, muito menos, limitar a duração diária da jornada de trabalho dos mesmos, que na grande parte dos países da Europa variava entre doze a dezesseis horas diárias, sendo utilizados crianças e mulheres em funções 
penosas. Os trabalhadores ficavam sujeitos a longas jornadas de trabalho, exercendo atividades perigosas insalubres, em ambientes nocivos à saúde, desprovidos de condições sanitárias e de higiene. Trabalhavam em minas de subsolo, fábricas metalúrgicas, fábricas de cerâmica e fábricas de tecelagem, sem qualquer limite ou proteção social.

Diante deste quadro caótico é que o Estado passou a se mobilizar e a interferir nas relações trabalhistas para proteger os trabalhadores, sendo certo que as primeiras leis de proteção aos trabalhadores foram exatamente as que se destinaram a limitar a duração da jornada de trabalho.

As condições de trabalho em termos gerais, evoluiu, e esses avanços ganharam eco com a instituição da Organização Internacional do Trabalho (OIT) pela Liga das Nações Unidas, após a Primeira Guerra Mundial, no que se conheceu como o Tratado de Versalhes (1919), pelo menos no tocante a jurisdição trabalhista, muito embora haja muitos entraves a serem superados, como por exemplo, os trabalhos escravos, disfarçados de trabalhos legais, muito encontrado em países em desenvolvimento.

No Brasil atualmente, há grande visibilidade, e até um grande embate de concepções ideológicas opostas, no tocante a "Lei da terceirização", vulgarmente batizada, ou a Lei no 13.429, de 31 de março de 2017. Segundo Araújo (2017), o texto da lei, recebeu críticas do presidente do Sindicato Nacional dos Auditores Fiscais do Trabalho, Carlos Fernando da Silva Filho, pois na visão deste, é um grande prejuízo as conquistas históricas trabalhistas e leva a precarização, porque o projeto não estabelece igualdade de direitos.

Tal afirmativa, se pode corroborar com a observação de Ricardo Antunes no texto: "O trabalho que estrutura o capital desestrutura a sociedade", de 24 de abril de 2015 , que versa sobre o PL 4330/04, que dispõe sobre a terceirização de atividades trabalhistas, ou seja, proposta que permite que qualquer atividade de uma empresa possa ser terceirizada, desde que a contratada esteja focada em uma atividade específica.

Representantes dos trabalhadores argumentam que a lei pode provocar precarização no mercado de trabalho. Empresários, por sua vez, defendem que a legislação promoverá maior formalização e mais empregos, porém não é um exercício fácil de compreensão, analisar os prós e contras a curto e médio prazo.

Importante destacar Antunes e Alves (2004), que fazem reflexões históricas sobre as relações de trabalho e o capital globalizado, onde se pode destacar que o proletariado convencional (até meados dos anos de 1950, 60 e 70) vem diminuindo com a reestruturação produtiva do capital, dando lugar a formas mais desregulamentadas de trabalho, reduzindo 
fortemente o conjunto de trabalhadores estáveis que se estruturavam por meio de empregos formais, ou seja, o que convencionou chamar de retração do binômio taylorismo/fordismo.

Os referidos autores também destacaram o "part-time", que durante os últimos anos (2015; 2016 e 2017), tem sido amplamente discutido nos meios de comunicação, como telejornais, rádios e internet. Tal denominação de trabalhadores são os terceirizados, subcontratados e suas formas análogas.

Tomando como base um olhar sobre o Estado brasileiro, principalmente nos anos de 1990, foi possível compreender o processo de precarização laboral o qual os trabalhadores nacionais foram submetidos. Esta precarização está intimamente ligada com as mutações empreendidas pela nova divisão internacional do trabalho, aos países de industrialização tardia (os da américa latina), fundada na exploração desumana da força de trabalho, concomitantemente com baixos salários, jornadas de trabalho num ritmo frenético

\subsection{PRECARIZAÇÃO DO TRABALHO DOS POLICIAIS E BOMBEIROS MILITARES}

As características da profissão militar (oficiais e praças), pode ser sintetizada, conforme descrito no site institucional da Força Expedicionária Brasileira (EXÉRCITO BRASILEIRO, 2017, s/p):

- $\quad$ Risco de vida;

- Sujeição a princípios rígidos de hierarquia e disciplina;

- Dedicação exclusiva;

- $\quad$ Disponibilidade permanente;

- $\quad$ Mobilidade geográfica;

- Vigor físico;

- Restrições a direitos trabalhistas.

Essas características embora sejam das forças armadas brasileiras (exército, marinha e aeronáutica), é incorporado pelas forças auxiliares (polícia militar e bombeiros). No ambiente militar, ou melhor, no cotidiano dos quartéis, é disseminado o espírito "castrense", onde os recrutas são doutrinados a desenvolver sentimentos patrióticos, e fundamentalmente o respeito a hierarquia e disciplina, pois tais premissas, são os sustentáculos desta organização.

Tomando como base os fundamentos marxianos de O Capital, e objetivando relacionar com a precarização do trabalho a qual militares também estão inseridos, que não realizam atividade produtiva, é válido iniciar com as perguntas que se segue: Mas que mercadorias o funcionalismo público produz? Mais especificamente ainda, qual mercadoria os policiais e bombeiros produzem? 
No primeiro setor, os profissionais da segurança pública, defendem os direitos individuais e coletivos, descritos na Carta Magna brasileira de 1988, preservam a ordem pública, a integridade das pessoas, o direito de ir e vir, a propriedade privada, portanto analogamente, a sociedade, representada pelo Estado, é o patrão destes profissionais, pois por meio dos impostos que a sociedade paga, financia a estrutura e o aparato da segurança pública, como maquinários, equipamentos, armamentos, munições e principalmente o salário, portanto é o braço direito do Estado, que exerce seu papel de controle social para que sejam mantido os elementos harmônicos de uma sociedade, os poderes legislativo, executivo e judiciário. E para corroborar Fraga (2006, p. 4):

[...] Ao se considerar a polícia como profissão, como uma especialização na divisão sociotécnica do trabalho, destaca-se que o policial é um sujeito que desenvolve um processo de trabalho. $\mathrm{O}$ trabalho do policial na sociedade produz um valor de uso (o serviço de segurança pública oferecido à sociedade) e um valor de troca (preço pago pelo seu empregador, o Estado, pelo seu serviço)[...].

Os trabalhadores ora em estudo, arriscam sua vida, comprometem sua qualidade da mesma, em jornadas de trabalho que muitas vezes, quiçá, a maioria das vezes, ultrapassam a carga horária semanal, se comparado com os trabalhadores regidos pela CLT brasileira, que é 44 horas semanais, de certo os militares são regidos por estatutos, o que então há quem diga que não cabe uma comparação, mas porque essa classe que vende a sua força de trabalho para o Estado, e que se submete em escalas de serviço de 12x36 (12 horas de trabalho e 36 horas de folga), $24 \times 48$ ( 24 horas de trabalho e 48 horas de folga), 24x72(24 horas de trabalho e 72 horas de folga), fora as escalas de serviço extraordinária e expedientes administrativos, estão excluídas deste benefício, ou melhor, do direito intrínseco ao ser humano, que é ter um limite de carga horária?

O fato é que existe uma grande polêmica, quando o assunto é o militar estadual, e isso se deve muito a falta de clareza na legislação, pois ao considerá-la de forma literal, nem Funcionário Público o militar pode ser considerado, pois essa categoria não se enquadra como "Funcionário Público", mas sim em uma classe especial denominada militares dos Estados, do Distrito Federal e dos Territórios, como prevê o artigo 42 da $\mathrm{CF}$, isto é corroborado ao observarmos seu lugar em separado na seção III, taxativamente como "Dos Militares dos Estados, Distrito Federal e Territórios", alijando-os assim, do termo funcionário público.

O estilo de vida do militar acaba gerando problemas no âmbito familiar e social, pois devido as peculiaridades da profissão, muitas das vezes é obrigado a abdicar de momentos de lazer (finais de semana e feriado) com sua família e se apresentar a sua Unidade, se necessário 
for, e caso não acate a ordem, está sujeito a penalidades administrativas, dentre outras, previstas em Código Penal Militar, instituída pelo Decreto-Lei nº 1.001, de 21 de outubro de1969.

Além da disponibilidade permanente ao trabalho, consequentemente lidando com suas restrições biológicas, devido ao cansaço, estresse, problemas familiares, os equipamentos e utensílios disponibilizados pela Instituição, com condições de emprego comprometidos (má gestão e/ou excesso de burocracia em processos licitatórios), coadunam negativamente para a precarização do trabalho. Tais combinações, contribuem para a desmotivação e desatenção ao serviço, tornando o militar uma potencial vítima nas suas atividades laborais.

Essas intempéries acima mencionadas contribuem para a precarização do trabalho? O que se entende por precarização? Tal expressão significa desvalorização, redução, diminuição, e associado ao termo "trabalho", remete a desvalorização do trabalho, flexibilização dos direitos trabalhistas, aumento da fragilidade do trabalhador diante o empregador.

Para Antunes (2009), o trabalhador precarizado se encontra em uma fronteira incerta entre ocupação e não ocupação, bem como de um incerto reconhecimento jurídico diante das garantias sociais, ou seja, uma flexibilização e uma desregulamentação dos direitos trabalhistas, que no Brasil já vem a completar quase três quartos de século. De certo, o referido autor dar ênfase nas relações de trabalho no segundo setor (regido pela CLT), porém é perfeitamente aplicável em alguns aspectos no primeiro setor, ou melhor, no serviço público realizado pelos militares estaduais, como por exemplo em Antunes (2009, p. 50):

\footnotetext{
[...] Dentre as distintas formas de flexibilização - em verdade precarização - podemos destacar a salarial, de horário, funcional ou organizativa, dentre outros exemplos. A flexibilização pode ser entendida como "liberdade da empresa" para desempregar trabalhadores; sem penalidades, quando a produção e as vendas diminuem; liberdade sempre para a empresa, para reduzir o horário de trabalho ou de recorrer a mais horas de trabalho; possibilidade de pagar salários reais mais baixos do que a paridade de trabalho exige; possibilidade de subdividir a jornada de trabalho em dia e semana, segundo as conveniências das empresas, mudando os horários e as características do trabalho (por turno, por escala, em tempo parcial, horário flexível etc.), dentre tantas outras formas de precarização da força de trabalho [...].
}

Logicamente que o funcionalismo público em comparação com os trabalhadores da iniciativa privada, ou melhor os "celetistas", levam uma desvantagem no quesito financeiro, porém possuem o que seus estatutos definem como "estabilidade", o que vem a ser uma espécie de garantia de manutenção em seu cargo, salvo motivos previstos nos incisos I, II e III, do parágrafo $1^{\circ}$ do artigo 41 da Constituição Federal de 1988. O funcionário público civil, concursado, adquire estabilidade após três anos de efetivo exercício. Dentro do militarismo estadual, quanto do das Forças Armadas há duas classes que interagem no ambiente de trabalho, os oficiais (que geralmente exercem a função de comando e gerenciamento das organizações 
militares) e os praças (que exercem a função de execução, ou seja, atividades de cunho operacional).

Os praças (classe composta por soldado, cabo, sargento e subtenente), segundo a Lei $\mathrm{n}^{\circ}$ 5.251 de 31 de Julho de 1985, que dispõe sobre o Estatuto dos Policiais-Militares da Polícia Militar do Estado do Pará, que também é estendido aos Bombeiros Militares, adquirem estabilidade após dez anos de efetivo serviço, e os oficiais (classe composta por tenente, capitão, major, tenente coronel e coronel), adquirem estabilidade após concessão pelo governador do estado a Carta Patente, geralmente após a conclusão do Curso de Formação de Oficiais, e o cumprimento de uma espécie de estágio como Aspitante a Oficial, que em média contando o curso de formação de três anos e o tempo de aspirantado, é concedida (estabilidade) em quatro anos. O Referido estatuto, dispõe também sobre a forma de ingresso, bem como o conjunto de direitos e deveres do policial militar, dentre outros assuntos inerente a carreira.

\section{METODOLOGIA}

A presente pesquisa, quanto a seu tipo, de acordo com Gil (1999), é exploratória, pois busca a familiarização de um determinado assunto, que ainda se tem pouca relevância literária, a fim de que se possa construir hipóteses, sobre o referido fenômeno que se tem como escopo a investigação.

Tal pesquisa exploratória, tem caráter qualitativa, onde se dividiu em três processos analíticos: estudo bibliográfico, estudo documental e a aplicação de questionário.

O estudo bibliográfico, foi realizado sobre as obras de Karl Marx (1983), principalmente ideias consubstanciadas em O Capital, bem como se valeu da obra de outros autores, como Ferreira (2012), Antunes (2009). Bem como estudo da legislação, como a Constituição Federal de 1988, leis estaduais do Pará, no tocante ao Estatuto dos Policiais Militares do Estado do Pará.

Quanto à pesquisa de campo optou-se por trabalhar com o Questionário semiestruturado, em razão da objetividade e por permitir a padronização das respostas, conforme apregoa Gil (1999). O questionário aplicado (conforme Apêndice A, p.21), contém quatorze perguntas, com o objetivo avaliar e analisar a opinião dos militares sobre o seu cotidiano de trabalho e as implicações de suas atividades laborativas no âmbito familiar e social. As quatorze perguntas aplicadas no questionário foram divididas em doze de múltipla escolha (fechada) e duas abertas (permitindo comentário). Sendo apresentadas em duas seções, a primeira, de identificação geral, informações pessoais quanto a sexo, faixa etária, nível de 
escolaridade, tempo de serviço público, Posto/Graduação no Corpo de Bombeiros Militar e faixa de renda salarial (totalizando seis perguntas).

A segunda parte do questionário, versa sobre as condições de trabalho no seio da organização, totalizando oito perguntas, seis de múltipla escolha e duas de múltipla escolha, porém podendo o entrevistado tecer comentário.

Para execução foi primeiramente solicitado ao Comando do $1^{\circ}$ Grupamento Marítimo Fluvial, autorização para que os militares da referida unidade bombeiro militar (UBM), preenchessem o questionário. O quartel do $1^{\circ}$ Grupamento Marítimo Fluvial - $1^{\circ} \mathrm{GMAF}$, possui quarenta militares, sendo três oficiais e trinta e sete praças. Os oficiais são compostos por dois capitães e um tenente. Os praças do $1^{\circ}$ GMAF, são compostos por dois subtenentes, dez sargentos, onze cabos e quatorze soldados. Tais números, estão atualizados até o dia 31 de outubro de 2017.

Devido a peculiaridade das atividades desenvolvidas pelo $1^{\circ} \mathrm{GMAF}$ e a dificuldade de conseguir que a totalidade dos militares respondessem o questionário, pois sempre há militares que estão afastados momentaneamente das atividades do quartel, seja por estarem de férias, licença especial ou licença de saúde, ou a folga do serviço, após completar vinte e quatro horas de plantão.

A aplicação do Questionário se deu no mês de novembro de 2017, foi preenchido o questionário impresso de avaliação das condições de trabalho dos militares do $1^{\circ} \mathrm{GMAF}$, que são uma amostra do universo que é a Segurança Pública, atividade desenvolvida, dentre outros, pelos Policiais e Bombeiros Militares. Vinte militares da referida UBM, preencheram o documento de estudo, o que corresponde a cinquenta por cento dos militares, ou melhor, uma amostra que representa a metade da totalidade de militares pertencente ao $1^{\circ}$ GMAF. Foi disponibilizado dez minutos para que os mesmos pudessem concluir a atividade, ou seja, o preenchimento do questionário impresso.

A seleção da amostra se deu entre Oficiais e Praças, do sexo masculino (não há militares do sexo feminino nesta unidade) e que estão no serviço ativo, ou seja, não afastados do serviço por férias, licença especial, licença saúde, ou cedido a outro órgão.

\section{ANÁLISE E DISCUSSÃO DE DADOS}

O $1^{\circ}$ Grupamento Marítimo Fluvial é um quartel pertencente ao Corpo de Bombeiros Militar do Estado do Pará, e tem como funções preponderantes, segundo a Lei n 5.731 , de 15 de dezembro de 1992 (que dispõe sobre a Organização Básica do Corpo de Bombeiros Militar 
do Estado do Pará), em seu artigo 35, a prevenção de acidentes e incêndios marítimo e fluvial. Com a evolução da Instituição e consequentemente a crescente demanda da sociedade, o Corpo de Bombeiros Militar do Estado do Pará, criou em 2006 (quatorze anos após a referida Lei acima destacada), uma UBM, especializada na prevenção, resgate e salvamento na área aquática, bem como: combate a incêndio em embarcações, mergulho de resgate, prevenção balneária (atividade de guarda-vidas, que é a prevenção de afogamentos e resgate de pessoas em mares, rios e lagos). A Tabela 1, a seguir, demonstra o quantitativo total de militares:

Tabela 1 - Corpo de Bombeiros - Mapa de Força do $1^{\circ}$ Grupamento Marítimo Fluvial, 2017

\begin{tabular}{lll}
\hline Cargo & Quantidade & Percentual \\
\hline Oficiais Superiores & 00 & $0 \%$ \\
Oficiais Intermediários & 02 & $5,0 \%$ \\
Oficiais Subalternos & 01 & $2,5 \%$ \\
Subtenentes e Sargentos & 10 & $25,0 \%$ \\
Cabos & 11 & $27,5 \%$ \\
Soldados & 14 & $35,0 \%$ \\
Total & $\mathbf{4 0}$ & $\mathbf{1 0 0 \%}$ \\
\hline
\end{tabular}

Fonte: Pesquisa de campo (nov, 2017)

Pode-se destacar, em relação aos dados apresentados na Tabela 1, que os militares que exercem atividades operacionais, elementos de execução: subtenentes, sargentos, cabos e soldados, correspondem a 92,5\% (chega-se ao resultando excluindo os oficiais) do universo de militares do referido Quartel, ou seja, a maior parte dos militares que integram o $1^{\circ}$ Grupamento Marítimo Fluvial são da classe dos praças.

No momento em que foi aplicado o questionário, os Oficiais não estavam presentes, em razão de estarem à disposição do Quartel do Comando Geral do CBMPA, dentre outras atividades inerentes aos seus respectivos cargos, ou seja, os três oficiais, que são titulares das três principais funções de gestão do $1^{\circ} \mathrm{GMAF}$, não responderam o questionário. Portanto a Tabela 2, a seguir, vem representar a amostra da Pesquisa de Campo:

Tabela 2 - Perfil dos Entrevistados presentes no $1^{\circ}$ GMAF, 2017

\begin{tabular}{lll}
\hline Cargo & Quantidade & Percentual \\
\hline Subtenentes e Sargentos & 05 & $25,0 \%$ \\
Cabos & 07 & $35,0 \%$ \\
Soldados & 08 & $40,0 \%$ \\
Total & $\mathbf{2 0}$ & $\mathbf{1 0 0 \%}$ \\
\hline
\end{tabular}

Fonte: Pesquisa de campo (nov, 2017)

Da amostra de vinte militares, expõe-se os dados a seguir. Primeiramente em relação a nível de escolaridade, em que o Gráfico 1, demonstra que a maioria dos militares possuem o nível médio de escolaridade (antigo $2^{\circ}$ Grau), ou seja, mais de $80 \%$, e menos de $20 \%$, são 
portadores de nível educacional superior e não houve registro de militares com nível fundamental e nem o nível que suplanta o superior, que é o de pós-graduação.

Gráfico 1 - Nível de Escolaridade dos Entrevistados - 2017

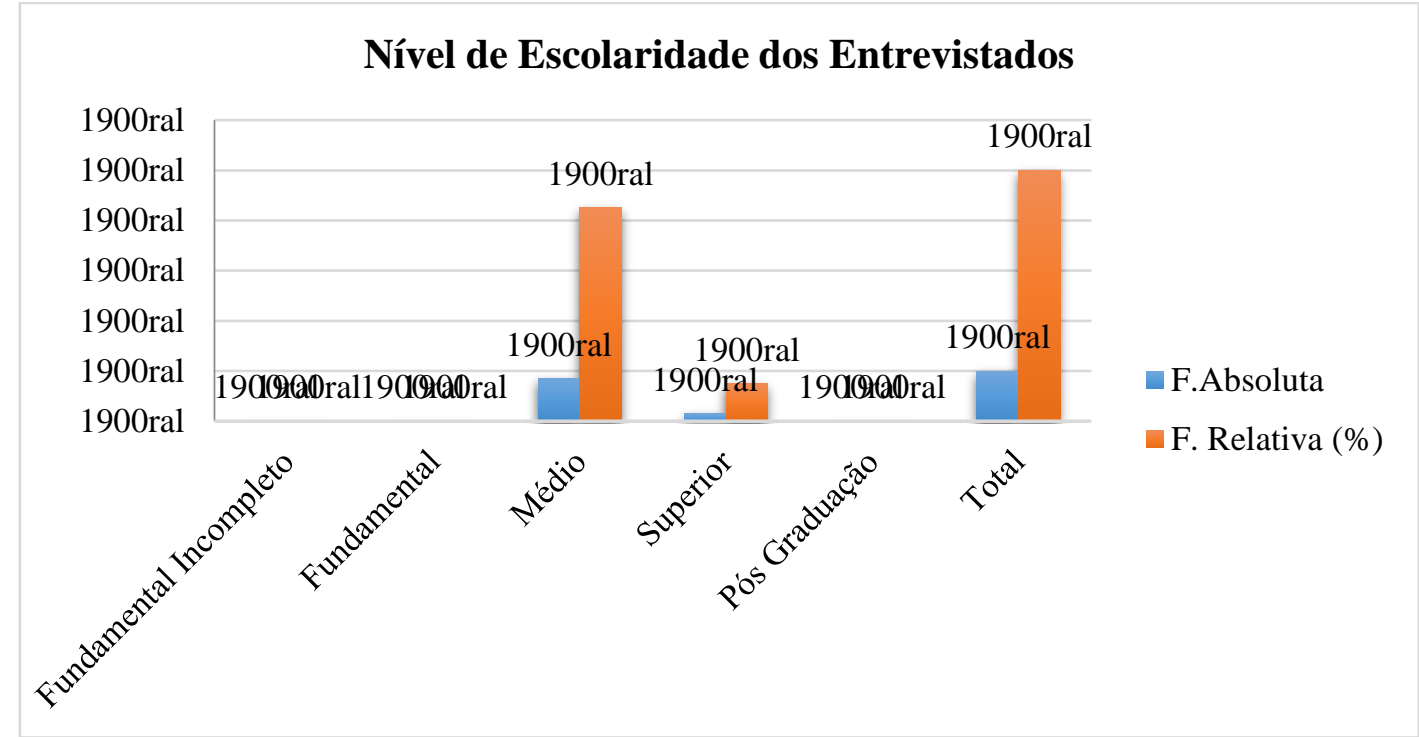

Fonte: Pesquisa de campo (nov, 2017)

Ainda tratando as informações gerais dos respondentes, verifica-se perfil 218 socioeconômico, onde se é classificado os militares por faixa de renda, conforme o Gráfico 2, abaixo:

Gráfico 2 - Faixa de Renda dos Entrevistados - 2017

\section{Faixa de Renda dos Entrevistados}

를.Absoluta 틀. Relativa (\%)

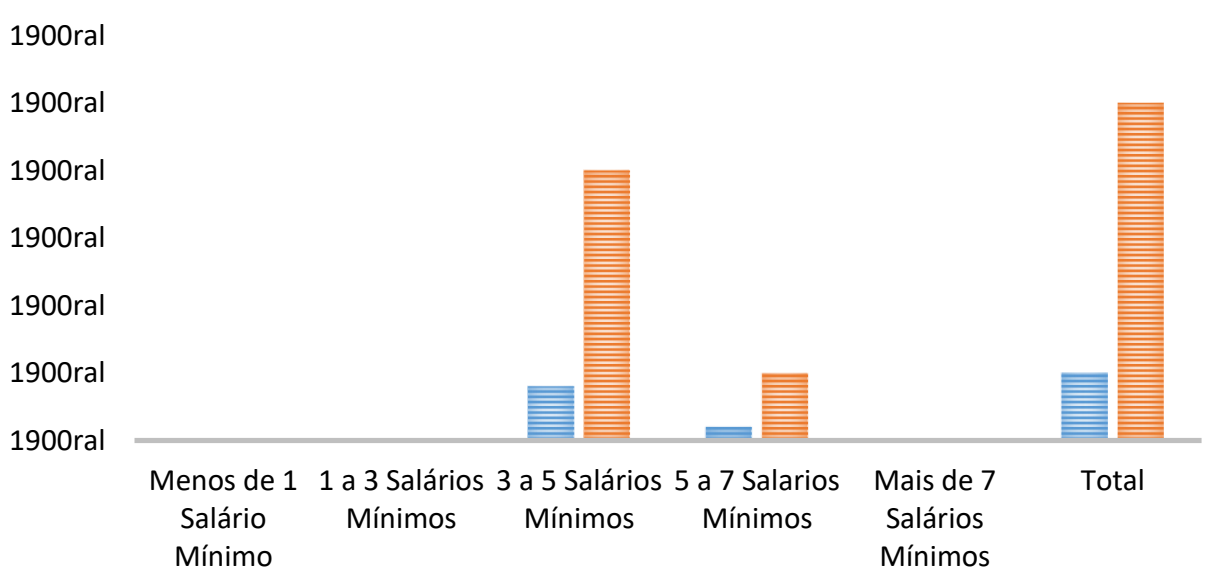

Fonte: Pesquisa de campo (nov, 2017)

Quanto a faixa de renda salarial, $80 \%$ ganham de 3 a 5 salários mínimos e $20 \%$ de 5 a 7 salários mínimos, ou seja, metade dos militares do $1^{\circ}$ GMAF (vinte) ganham até 7 salários 
mínimos. É válido ressaltar que foi levado em consideração a renda salarial bruta, sem os descontos e deduções legais, tais como imposto de renda, fundos de previdências, pensões alimentícias ou empréstimos consignados. É válido ressaltar que os valores são baseados no salário mínimo de 2014, pois o Governo do Estado do Pará, não reajustou os vencimentos básicos com as atualizações anuais dos salários mínimos seguintes: 2015, 2016 e 2017, gerando grandes perdas salariais e consequentemente perda do poder aquisitivo.

Dos vinte militares que foram entrevistados na Pesquisa de Campo, quanto a idade, foi constatado que dezesseis (80\%), estão na faixa etária de 35 a 45 anos e quatro (20\%) estão na faixa etária de 25 a 35 anos. Portanto faixa etária da fase adulta em que o homem, em geral, está em pleno vigor e capacidade técnico profissional.

Na segunda seção do questionário, na qual foram formuladas oito perguntas que versam sobre as condições de trabalho no ambiente militar, iniciou com a pergunta: As condições ambientais do seu local de trabalho são satisfatórias? Nesta pergunta buscou a opinião dos militares, onde os mesmos atribuiriam uma nota que varia entre 1 a 5 (condições insatisfatórias/péssimas a condições satisfatórias/excelente), quanto a temperatura, espaço, mobiliário, higiene, instalações sanitárias.

Tabela 3 - Notas atribuídas pelos entrevistados sobre o ambiente de trabalho, 2017

\begin{tabular}{llllc}
\hline Ítens avaliados na UBM & Nota 1 a 2 & Nota de 3 a 4 & Nota 5 & Total \\
\hline Temperatura & 07 & 10 & 03 & 20 \\
Espaço & 02 & 14 & 04 & 20 \\
Mobiliário & 09 & 07 & 04 & 20 \\
Higiene & 08 & 08 & 04 & 20 \\
Instalações Sanitárias & 07 & 07 & 06 & 20
\end{tabular}

Fonte: Pesquisa de campo (nov, 2017)

Nesta primeira pergunta, observou-se que a referida organização não teve o conceito "satisfatório/excelente" pela maioria dos entrevistados em nenhum dos itens indagados. Obteve o maior percentual no item "Instalações Sanitárias", onde aproximadamente 30\%, entenderam que a organização tem a excelência no referido quesito. Portanto os conceitos que houve uma concentração de atribuições, foram os que variam de 3 a 4, que seria o meio termo, ou conceitos de regular a bom. O item de pior avaliação dos militares foi o tocante ao mobiliário, que $45 \%$ dos entrevistados consideraram ser de condições insatisfatórias/péssimas.

A segunda pergunta da segunda parte do questionário, vem com a inquirição: Os equipamentos e materiais disponibilizados pela Instituição para o emprego no dia a dia, quanto ao seu estado de conservação, apresenta-se? Dez entrevistados, atribuíram nota de 3 a 4 , regular/bom, o que representa $50 \%$ dos entrevistados, cinco militares $(25 \%)$ consideraram que 
o estado de conservação dos equipamentos e materiais estão num nível máximo de excelência, e outros cinco (25\%), já entendem de maneira diametralmente oposta, que o estado de conservação dos equipamentos e materiais estão de maneira insatisfatória.

Na tabela 4, buscou a integração de cinco perguntas, que se conectam, no sentido de que, há nelas um grande potencial avaliador sobre a satisfação do profissional, haja vista que estão nestas perguntas temas como volume de trabalho, ou seja, a quantidade/intensidade de tarefas que o militar realiza, horas trabalhadas, relações interpessoais (indaga sobre como o entrevistado avalia a cooperação e a interação entre os colegas), investimento da instituição em treinamento para aprimoramento da execução de seu trabalho, e por fim, a nota que o entrevistado atribui para instituição no tocante a valorização das ideias e sugestões emanadas por eles.

Tabela 4 - Notas atribuídas pelos entrevistados sobre trabalho e valorização do profissional, 2017

\begin{tabular}{lllll}
\hline Ítens avaliados na UBM & Nota 1 a 2 & Nota de 3 a 4 & Nota 5 & Total \\
\hline Volume de trabalho & 11 & 07 & 02 & 20 \\
Horas trabalhadas & 13 & 06 & 01 & 20 \\
Relações Interpessoais & 02 & 09 & 09 & 20 \\
Treinamento e qualificação & 05 & 08 & 07 & 20 \\
Valorização de ideias & 08 & 06 & 06 & 20 \\
\hline
\end{tabular}

Fonte: Pesquisa de campo (nov, 2017).

Nos itens, "Volume de trabalho" e "horas trabalhadas" evidenciaram, respectivamente, que $55 \%$ e $65 \%$ dos entrevistados estão insatisfeitos com a quantidade de trabalho e a respectiva jornada de trabalho, no sentido oposto do entendimento, somente dois militares ou 10\%, acredita que o volume de trabalho está em condições satisfatórias/excelentes, bem como somente um único entrevistado, $5 \%$, entendeu que as horas trabalhadas não apresentam excesso.

Quanto a pergunta "Em que medida você está satisfeito com o ambiente de trabalho (relações entre colegas - cooperação e interação)?, dezoito militares, ou 90\%, consideram que varia de regular para excelente o referido item, haja vista, que nove ou $45 \%$, entenderam que a relação interpessoal é de regular/bom no ambiente de trabalho e outros nove ou $45 \%$, creem que é excelente a relação interpessoal na organização, sobrando então dois militares ou $10 \%$ dos entrevistados consideram ser péssimo as relações entre os colegas, bem como a cooperação e interação.

No quesito "treinamento e qualificação", foi equilibrada a avaliação, no tocante aos conceitos atribuídos, pois $40 \%$ dos entrevistados entenderam que o investimento da instituição em treinamento e qualificação está num nível de regular/bom, 35\% dos entrevistados acham que o investimento da organização em treinamento e aperfeiçoamento dos seus integrantes está 
num nível de excelência e 25\%, consideram que a instituição está num nível insatisfatório no âmbito do investimento em aprimoramento dos seus servidores.

Considerando a pergunta "Sente que suas ideias e sugestões são ouvidas/valorizadas pela Instituição? Por que?, não houve comentários dos entrevistados, somente atribuíram a nota variante de 1 a 5. Igualmente ao quesito anterior, se registrou um equilíbrio nas respostas, dos vinte entrevistados, oito (40\%), acreditam que suas ideias não são ou pouco são valorizadas, seis (30\%), já entendem que o nível de aceitação de suas ideias estão numa escala de regular/bom e mais seis (30\%), consideram ser excelente o nível de acolhimento de suas ideias e sugestões para a Instituição.

$\mathrm{Na}$ última pergunta, "Em seu tempo livre (extra ambiente militar), quais atividades fazem parte de sua programação semanal?" (Pode marcar mais de uma resposta), considerando que a pergunta é aberta, permitindo mais de uma marcação, e o total de entrevistados são vinte, poderia na hipótese de todos marcarem as seis alternativas, daria 20 assinalações para cada alternativa. Porém, futebol e passeio com a família, registraram cada 15 assinalações, ou seja, 75\% dos militares em suas horas de lazer dedicam a prática de futebol e ao passeio com os familiares. Em "estudo", foram marcadas 10, ou seja, dos vinte entrevistados, $50 \%$ dedicam seu tempo livre ao estudo, "lazer", registrou também dez assinalações, e "cinema" registrou oito votos $(40 \%)$ e por último veio a opção "outros" com quatro marcações $(20 \%)$.

Por si só, a profissão já traz consigo inúmeros riscos, não há como pensar na atividade policial sem atrelar a ela os riscos que a cerca, sendo no Pará - e no Brasil -, sem dúvidas, uma dos trabalhos mais perigosos dada a realidade social em que vivemos (SOUZA, 2018). Tanto a polícia, como de certa forma os bombeiros, são organizações que tem como principal objetivo zelar por uma ordem social, ao sofrerem com a omissão por parte do Estado em questão da gestão de seus recursos, o trabalho dos policiais e bombeiros, por exemplo, que deveria ser uma solução social, torna-se um problema (CERQUEIRA; LOBÃO; CARVALHO, 2005)

\section{CONSIDERAÇÕES FINAIS}

O corrente estudo, buscou analisar a visão dos integrantes da organização militar do Corpo de Bombeiros sobre as condições laborais, por meio de um questionário. Logicamente que os resultados revelam o que os militares específicos da UBM (unidade bombeiro militar) sentem, e o Corpo de Bombeiros Militar do Pará, segundo o site da Instituição, (CBMPA, 2017), possui 42 UBM's, contando Região Metropolitana de Belém e Interior do Estado. A Polícia Militar do Pará, segundo o site institucional (PMPA, 2017), possui 36 Batalhões de Polícia 
Militar entre capital e interior, que são os chamados Órgãos de Execução, porém a referida instituição tem um organograma ainda mais complexo, pois fora estes, possuem outros órgãos especializados no policiamento ostensivo, o que torna complexo uma análise mais consistente sobre se a segurança pública em geral está num processo de Precarização no que tange as condições de trabalho.

O problema gerado pelo sucateamento dos órgãos de segurança pública, acabam por levar esses profissionais a se submeter a realidades subumanas, esse cenário gera um efeito cascata que acaba na desvalorização da profissão, gerando um olhar negativo da opinião pública para com o trabalho dos policiais e afins, essa falta de reconhecimento afasta ainda mais a instituição da sociedade, sem o apoio da população torna-se muito mais difícil buscar soluções para a questão da precarização desses órgãos, pois não se conhece a realidade em que esses indivíduos estão inseridos por meio do mercado de trabalho.

Somente o investimento do Estado no que concerne à valorização profissional, concatenado com a melhoria das condições estruturais do ambiente das organizações, poderá os militares estaduais dar uma resposta mais efetiva a sociedade e assim cumprir seu dever constitucional, evitando assim a precarização do trabalho, e fundamentalmente evitando o adoecimento em decorrência da atividade, tal como Síndrome de Burnout, ferimentos, mutilações, baleamentos e o crescente número de mortes de Policiais e Bombeiros na execução de suas atividades. 


\section{REFERENCIAS}

ANTUNES, R; ALVES, G. As Mutações no Mundo do Trabalho na era da Mundialização do Capital. Educação e Sociedade, Campinas, v. 25, n. 87, p. 335-351, mai/ago. 2004.

ANTUNES, R. Os Sentidos do Trabalho. 6. ed. São Paulo: Boitempo Editorial, 2012. (Coleção Mundo do Trabalho).

ANTUNES, R. O Trabalho, sua Nova Morfologia e a era da Precarização Estrutural. Revista Theomai, Buenos Aires, $\mathrm{n}^{\circ}$ 19, $1^{\circ}$ semestre, 2009.

ANTUNES, R. O Trabalho que estrutura o Capital Desestrutura a Sociedade. Revista Esquerda Socialista, 2017. Disponível em: https://esquerdasocialista.com.br/ricardo-antuneso-trabalho-que-estrutura-o-capital-desestrutura-a-sociedade/. Acesso em: 12 de outubro de 2017.

BRASIL. Constituição da República Federativa do Brasil. Promulgada em 05 de outubro de 1988. Disponível em: http://www2.camara.leg.br/legin/fed/consti/1988/constituicao-19885-outubro-1988-322142-publicacaooriginal-1-pl.html. Acesso em: 19 nov. 2017.

BRASIL. Exército Brasileiro. Características da profissão militar. Disponível em: http://www.eb.mil.br/caracteristicas-da-profissao-militar. Acesso em: 18 de ago 2019.

CERQUEIRA, D.; LOBÃO, W.; CARVALHO, A. X. O jogo dos sete mitos e a miséria da segurança pública no Brasil. Rio de Janeiro, IPEA, 2005. (Texto Para Discussão $N^{\circ}$. 1144).

CHIAVENATO, Idalberto; Introdução à Teoria Geral da Administração. Rio de Janeiro: Elsevier, 2003.

FERREIRA, J.W. Sociologia do Trabalho. Ijuí: Ed. Unijuí, 2012. (Coleção educação a distância. Série livro-texto).

FRAGA, C. K. Peculiaridades do trabalho policial militar. Revista Virtual Textos \& Contextos, Porto Alegre, v. 5. n. 2, 2006. Disponível em:

http://revistaseletronicas.pucrs.br/fass/ojs/index.php/fass/article/view/1033/812. Acesso em: 18 ago. 2019.

GIL, A. C. Métodos e técnicas de pesquisa social. 5. ed. São Paulo: Atlas, 1999.

HUNT, E. K; SHERMAN, H. J. História do Pensamento Econômico. Petrópolis: Ed. Vozes, 2005.

MARX, K. O Capital. São Paulo: Abril Cultural, 1985. Tomo I, vol. I.

MARX, K. O Capital - Capítulo VI (Inédito). São Paulo: Ed. Ciências Humanas, 1978.

NAPOLEONI, C. Lições sobre o capítulo sexto (inédito) de Marx. São Paulo: Livraria Editora Ciências Humanas, 1981.

PAULO NETTO, J.; BRAZ, M. Introdução à Economia Política. São Paulo: Cortez Editores, 2006. 
PARÁ (Estado). Corpo de Bombeiros. Histórico. Disponível em:

http://www.bombeiros.pa.gov.br/unidades/. Acesso em: 19 de abr 2019

PARÁ. (Estado). Lei 5.251 de 31 de julho de 1985. Estatuto dos Policiais Militares. FASPM, disponível em:

http://www.faspm.pa.gov.br/sites/default/files/estatuto_do_policiais_militares.pdf. Acesso em:19 abr, 2019.

PARREIRAS, L. P. Qualidade de vida no trabalho dos alunos sargentos do corpo de bombeiros militar de Santa Catarina. Santa Catarina: CEBM, 2011.

PARÁ (Estado). Policia Militar do Pará. Legislação Policial Militar. Disponível em: https://www.pm.pa.gov.br/?q=node/1351. Acesso em: 19 ago 2019.

SOUZA, C. M. A violência contra as instituições e aos agentes que atuam diretamente na segurança pública. 2018. Trabalho de Conclusão de Curso (Especialização em Gestão Integrada da Segurança Pública) - Universidade do Sul de Santa Catarina, Brasília, 2018. 


\section{APÊNDICE A}

\section{QUESTIONÁRIO DO ENTREVISTADO}

\section{1 - Identificação (Informações Gerais)}

Favor marcar com um $\underline{\mathbf{X}}$ somente em uma única resposta que melhor se apresente para você.

\subsection{Sexo:}
Masculino
$\square$ Feminino

1.2 Faixa de idade:
Até 25 anos
$\square$ De 25 a 35 anos
De 35 a 45 anos
De 45 a 60 anos
$\square$ Acima de 60 anos

\subsection{Nível de Escolaridade}
Doutorado

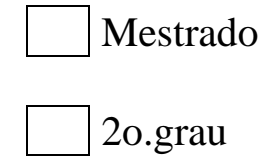
$\square$ Especialização
$3^{\circ}$ grau
2o.grau
Outro

1.4 Tempo em que você está no Corpo de Bombeiros Militar do Pará:

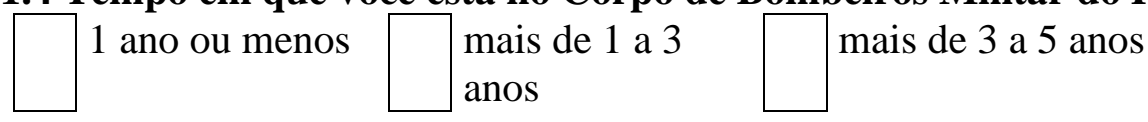

mais de 5 a 10 anos

mais de 10 anos

\subsection{Seu Posto/Graduação no CBMPA:}

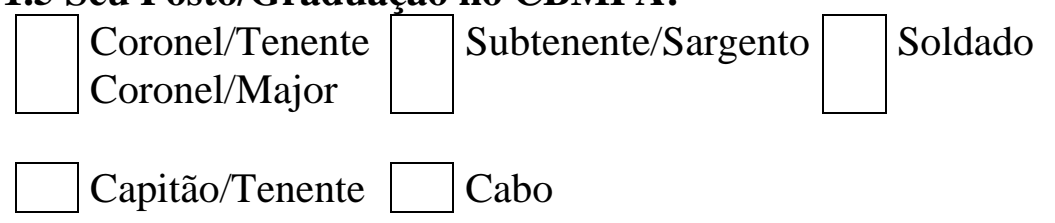

\subsection{Sua faixa salarial:}

\begin{tabular}{|c|c|c|}
\hline $\begin{array}{l}\text { Menos de } \\
\text { 1salário mínimo }\end{array}$ & $\begin{array}{l}\text { De } 3 \text { a } 5 \text { salários } \\
\text { mínimos }\end{array}$ & $\begin{array}{l}\text { Mais de } 7 \text { salários } \\
\text { mínimos }\end{array}$ \\
\hline $\begin{array}{l}\text { Entre } 1 \text { e } 3 \\
\text { salários mínimos }\end{array}$ & $\begin{array}{l}\text { De } 5 \text { a } 7 \text { salários } \\
\text { mínimos }\end{array}$ & \\
\hline
\end{tabular}

\section{2 - Condições de Trabalho}

As questões a seguir estão em escala de 1 a 5, Marque com X apenas um numero na escala. 
Lembre-se que 1 corresponde a "condições insatistatórias/péssimas" e 5 corresponte a "condições satisfatórias/excelentes"

2.1 As condições ambientais do seu local de trabalho são satisfatórias?

Temperatura:

\begin{tabular}{|l|l|l|l|l|}
\hline 1 & 2 & 3 & 4 & 5 \\
\hline
\end{tabular}

Espaço:

\begin{tabular}{|l|l|l|l|l|}
\hline 1 & 2 & 3 & 4 & 5 \\
\hline
\end{tabular}

Mobiliário:

\begin{tabular}{|l|l|l|l|l|}
\hline 1 & 2 & 3 & 4 & 5 \\
\hline
\end{tabular}

Higiene:

\begin{tabular}{|l|l|l|l|l|}
\hline 1 & 2 & 3 & 4 & 5 \\
\hline
\end{tabular}

Instalações sanitárias:

\begin{tabular}{|l|l|l|l|l|}
\hline 1 & 2 & 3 & 4 & 5 \\
\hline
\end{tabular}

2.2 Os equipamentos e materiais disponibilizados pela Instituição para o emprego no dia a dia, quanto ao seu estado de conservação, apresenta-se:

\begin{tabular}{|l|l|l|l|l|}
\hline 1 & 2 & 3 & 4 & 5 \\
\hline
\end{tabular}

2.3 Você se sente satisfeito em relação ao volume de trabalho que realiza?

\begin{tabular}{|l|l|l|l|l|}
\hline 1 & 2 & 3 & 4 & 5 \\
\hline
\end{tabular}

2.4 Em que medida você está satisfeito com o ambiente de trabalho (relações entre colegas - cooperação e interação)?

\begin{tabular}{|l|l|l|l|l|}
\hline 1 & 2 & 3 & 4 & 5 \\
\hline
\end{tabular}

2.5 Em que medida você está satisfeito com o ambiente de horas trabalhadas? 


\begin{tabular}{|l|l|l|l|l|}
\hline 1 & 2 & 3 & 4 & 5 \\
\hline
\end{tabular}

2.5 A quantidade de treinamento oferecida pela coorporação é suficiente para aprimorar a execução de seu trabalho?

\begin{tabular}{|l|l|l|l|l|}
\hline 1 & 2 & 3 & 4 & 5 \\
\hline
\end{tabular}

Comentário:

2.6 Sente que suas idéias e sugestões são ouvidas/valorizadas pela instituição? Por que?

\begin{tabular}{|l|l|l|l|l|}
\hline 1 & 2 & 3 & 4 & 5 \\
\hline
\end{tabular}

2.7 Em seu tempo livre (extra ambiente militar), quais atividades fazem parte de sua programação semanal? (PODE MARCAR MAIS DE UMA RESPOSTA)

( ) estudo

( ) lazer

( ) cinema

( ) futebol

( ) passeio com a família

( ) Outros: 